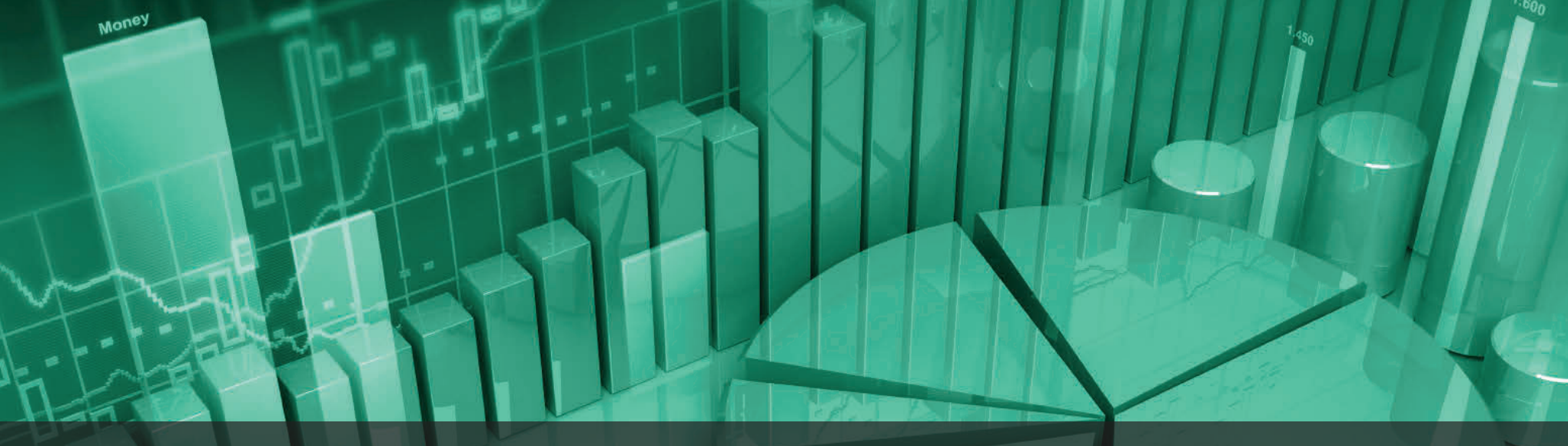

\section{NZX Joins the Race to Minimise Tick Size}

By Hamish D. Anderson

Hamish Anderson is an Associate Professor in Finance at Massey University, New Zealand

In 2011 , the New Zealand Exchange (NZX) reduced the minimumticksize from $\$ 0.01$ to $\$ 0.005$ forseventeendual-listed and propertystocks, with thestated objective of boosting NZX liquidity. After controlling for firms matched on similar liquidity characteristics, both spread and depth significantly decline, and there is some evidence of higher turnover. However, smaller firms do not enjoy the same liquidity benefits as larger firms. For example, smaller firms and those with greaterilliquidity priorto thetickchange, experience deteriorationinturnoverafterthe change. Keywords: Tick size, Liquidity, Spread, Depth, Turnover

1. Introduction

In March 2011, the NZX joined a world-wide race rather than NZX. As the head dealer for Craigs Investment to minimise tick size. Tick size, the smallest incremental Partners stated.

change in a shate pice has been sliced and diced by humerous stock exchanges around the world over the last numerous stock exchanges around the world over the last wo decades. The American Stock Exchange initiated this trend in 1992 by reducing tick size from 1/8th in a dollar to $1 / 16$ th for low priced stocks, before progressively rolling it out all stocks by 1997. The New York Stock Exchange whose tick size had remained unchanged for more than 200 years adopted the $1 / 16$ th tick size in 1997, which was further reduced to one cent in 2001. The race to ever lower tick sizes has been joined by numerous stock exchanges around the world, including those in Australia, Canada, United Kingdom, Tokyo, Taiwan and Hong Kong.

When extending the initial pilot scheme in October, 2011 Mark Weldon (former CEO of NZX) announced:

"...the reduced price steps had a positive impact on liquidity in the (initial five) selected stocks, which is good news for the companies, for investors and our wider markets.

We expect to see the same positive liquidity impact for these (additional 12) stocks too."

The scheme matches a similar 2005 ASX half-cent tick change that made it attractive for institutional investors to transact dual-listed stocks such as Telecom on the ASX
"Having to leave half-a-cent in Australia is detrimental to New Zealand liquidity". And this is "one of the major. but unspoken reasons why the scheme was introduced." (Krupp, 2011)

Investors are likely to be interested in bid-ask spread and depth as these directly impact on their total trading costs and ability to trade at the best available prices. International empirical studies typically show conflicting liquidity impacts when tick size is reduced, with spread narrowing (Chung, Charoenwong, and Ding, 2004 Aitken and Comerton-Forde, 2005) but depth at the best available prices declining (Goldstein and Kavajecz, 2000: Pan, Song and Too, 2012). In contrast to investors, motive for changing tick size is to boost turnover as a significant portion of their income is derived from turnover. However, the theoretical and empirical literature surrounding turnover changes is mixed. On one hand, reducing spreads and therefore lower trading costs may encourage investors to trade more, thereby boosting urnover. While on the other, liquidity providers may place orders further from the best available prices to protect their return or simply discontinue providing liquidity in the form of limit orders thereby reducing trading activity (Harris, 1997). Ahn, Cao, and Choe, (1996) find no change in trading activity in AMEX stocks, while Hsieh, Chung and Lin (2008) find significant declines in trading activity in Taiwan when tick size is reduced.

In addition, research also reveals that the liquidity benefits of lowering tick size are not shared equally by firms. Larger firms with higher trading volume and those that consistently trade at spreads equal to the minimum tick size prior to the change enjoy the greatest liquidity improvement (Chung, Charoenwong, and Ding, 2004). In contrast, smaller firms with low trading volumes experience a worsening of liquidity (Aitken and Comerton-Forde, 2005).

\section{Data \& Method}

The three main liquidity variables used to explore the change in tick size impact in this paper are: percentage quoted spread, depth and turnover. The percentage quoted spread is calculated as follows:

$$
\text { Quoted spread } \%=\frac{\left(\mathrm{Ask}_{\mathrm{j}, \mathrm{t}}-\mathrm{Bid}_{\mathrm{j}, \mathrm{t}}\right)}{\left(\mathrm{Ask}_{\mathrm{j}, \mathrm{t}}+\mathrm{Bid}_{\mathrm{j}, \mathrm{t}}\right) / 2}
$$

where Bid, and Ask, are the closing bid and ask quotes for stock $j$ on day $t$. Depth is the dollar value of depth a the best available bid and ask quotes immediately prior to each trade. Daily depth is then calculated for each stock by averaging the depth immediately prior to all trades in a given day. The third measure, turnover is the aggregate dollar value of all trades in a stock on a given day.

An event study method similar to Ahn, Cao, and Choe, (1996) compares the daily average for a liquidity variable by stock over the 120 trading days prior to the effective date (pre-period) of the tick change with 120 trading days after this date (post-period). The average across all eligible

\section{Findings}

This section first discusses the liquidity metrics that investors are likely to be concerned with, followed by the liquidity metric stock exchanges are most interested in. As previously mentioned, investors are likely to be concerned with the cost of trading (spread) and their ability to execute their orders at the best available prices (depth). In contrast stock exchanges will be more interested in turnover which is a key determinant of their revenue.
The final pool of 17 firms eligible to trade at half-cent Thements include some of the NZX's largest, most frequently traded stocks such as Telecom and Auckland Airport through to small, illiquid stocks like Kermadec Property Fund and CDL Investments (see Appendix for the complete list of eligible stocks). Understanding the impact of reducing the minimum tick on stocks exhibiting these varying size and liquidity characteristics can inf policy decisions. This paper shows that not all eligibe fims ans. This paper shows that not al elible fims gearler stocks and those with greater illiquidity prior to the tick change tend to fare worse after the reduction in tick size compared to larger more liquid stocks.

stocks in the pre- and post-periods are reported in Table 1. Given the relatively small sample sizes, the Wilcoxon signed rank test measures the statistical significance between preand post-period differences for each liquidity variables.

To control for possible market wide liquidity changes over the period examined, each eligible stock in the sample is also matched with a stock that is not eligible to trade at half cent increments. For each eligible stock, an ineligible stock is selected that is matched on size and liquidity characteristics. Wilcoxon-Mann-Whitney z-score is used to est whether the difference of differences is significant.

The daily closing stock prices, market capitalisation furnover and closing bid and ask prices are obtained from the NZX Company Research Database. Depth at the best bid and ask prices immediately prior to each trade is Pacific (SIRCA) for each stock.

Table 1 reports the pre- and post-period averages for the three liquidity variables, along with the difference between these two periods. Panel A and B show the averages for the eligible and ineligible matched control stocks respectively, while Panel $\mathrm{C}$ highlights whether the difference of differences between these two samples is significant. 
Table 1: Changes in Stock Liquidity Characteristics

\begin{tabular}{|c|c|c|c|c|}
\hline & Pre-period & Post-period & Difference & Signed Rank p-value \\
\hline Percentage Quoted Spread & $1.62 \%$ & $1.15 \%$ & $-0.47 \%$ & $0.000 \cdots$ \\
\hline Dollar depth & $\$ 141,893$ & $\$ 70,844$ & $-\$ 71,049$ & $0.000 \cdots$ \\
\hline Turnover & $\$ 2,061,335$ & $\$ 2,667,746$ & $\$ 606,411$ & 0.089 * \\
\hline \multicolumn{5}{|c|}{ Panel B: Ineligible Matched Control Stocks } \\
\hline & Pre-period & Post-period & Difference & Signed Rank p-value \\
\hline Percentage Quoted Spread & $1.26 \%$ & $1.43 \%$ & $0.17 \%$ & $0.081^{*}$ \\
\hline Dollar depth & $\$ 31,039$ & $\$ 27,996$ & $-\$ 3,043$ & $0.045 \cdots$ \\
\hline Turnover & $\$ 1,872,075$ & $\$ 2,171,774$ & $\$ 299,699$ & 0.644 \\
\hline \multicolumn{5}{|c|}{ Panel C: Difference of Eligible less Matched Control Stocks } \\
\hline & Eligible Stocks & Control Stocks & Difference & z-score \\
\hline Percentage Quoted Spread & $-0.47 \%$ & $0.17 \%$ & $-0.64 \%$ & $-4.33 \cdots$ \\
\hline Dollar depth & $-\$ 71,049$ & $-\$ 3,043$ & $-\$ 68,006$ & $-3.89 \cdots$ \\
\hline Turnover & $\$ 606,411$ & $\$ 299,699$ & $\$ 306,712$ & 1.38 \\
\hline
\end{tabular}

In the period leading up to the tick change, the average capture over $90 \%$ of these trading cost savings 18 of the quoted spread for eligible stocks was $1.62 \%$ and this drops 17 stocks are characterised as large based on a market to $1.15 \%$ when half-cent tick size is allowed. While the capitalisation over $\$ 500$ million).

$0.47 \%$ decrease in spread is statistically significant, it also in contrast to those stocks eligible to trade at half-cent represents an economically significant reduction in investor increments, the ineligible matched stocks experienced trading costs. Multiplying each stock's change in spread by marginal significant increase in spreads of $0.17 \%$ over the its average daily volume after the tick reduction reveals an mame period. As such, the eligible stock spread reduction is average daily saving of $\$ 108,937$ or more than $\$ 27$ million-

Figure 1 graphically shows the average quoted spread over 24 fortnightly intervals centred on the effective tick size change period (represented by the vertical line in Figure 1). The graph clearly highlights an immediate reduction in quoted spread after stocks became eligible to trade at half cent increments, and these smaller spreads persist for the next six months.

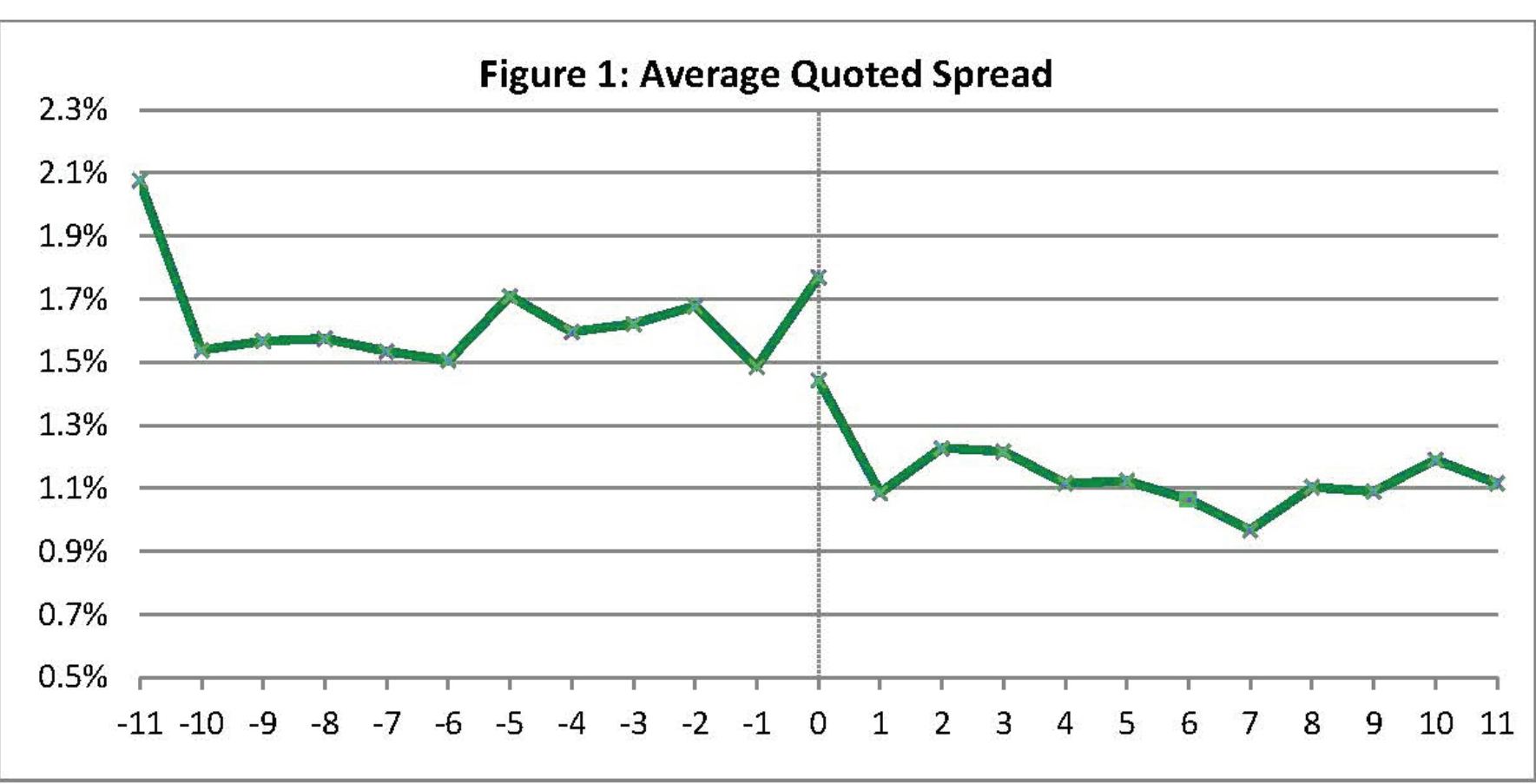

Investors may also be concerned with the ability to fill impact on depth Figure 2 shows average depth over 12 their orders at the best available prices. Lower depth fortnightly periods on either side of the half-cent effective means that investors may have to go deeper into the order date. Average depth immediately prior to a trade falls book when seeking to fill market orders. Table 1 highlights substantially during the first two weeks of the half cent tick that average depth in the post-period is less than half that change as shown on the vertical line. However, depth in the pre-period. Reduction in depth remains significant, consistently falls throughout the six month post-period reduction in depth as shown in Table 1, Panel C.

However, one could reasonably expect depth to halve, given the halving of the tick size. This analysis can't rule out the possibility that the combined depth within one cent range on the bid and ask is not signifcanty difterent cent range on the bid and ask is not signifcantly ditferen to the pre-period depth. To gain further insight into the approximately a quarter of the average pre-period depth, making it increasingly difficult for investors to fill orders at the best available prices. This would imply that investors would have to split their trades into smaller parcels to ensure they execute their orders at the best price available. And this is what happened. The average trade size in dollars dropped by $19 \%$ on average during the post-period.

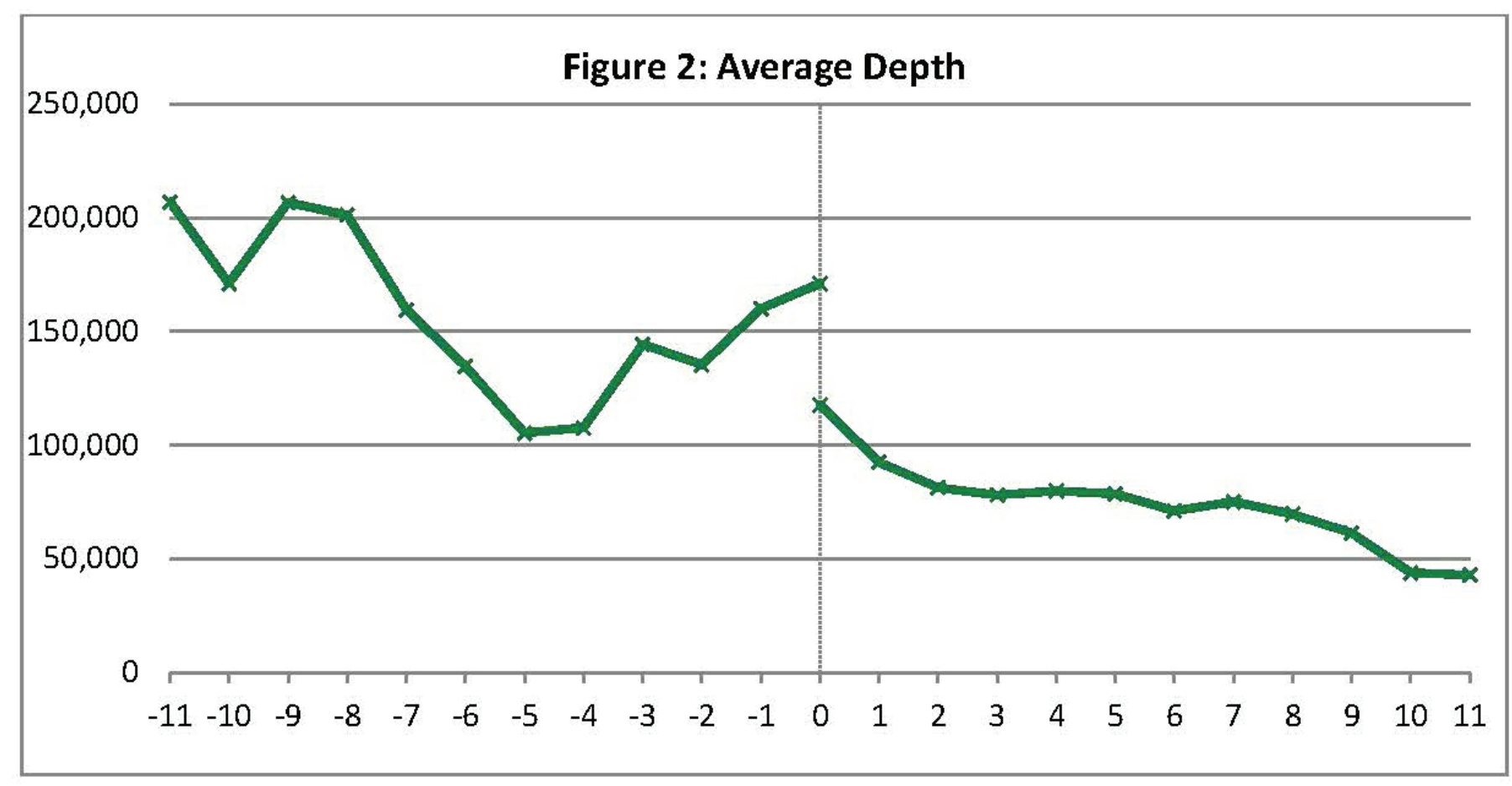

As mentioned in the introduction, the NZX's primary motivation to reduce tick size would be to boost turnover as this directly impacts on their revenues. We find that average daily turnover across all eligible stocks is $29.4 \%$ higher after the change. Figure 3 shows the average daily turnover for eligible stocks during fortnightly intervals. We see that after an initial boost in turnover immediately after the tick change, turnover then slumped before recovering to higher than pre-period levels during the 3-6 month period. 


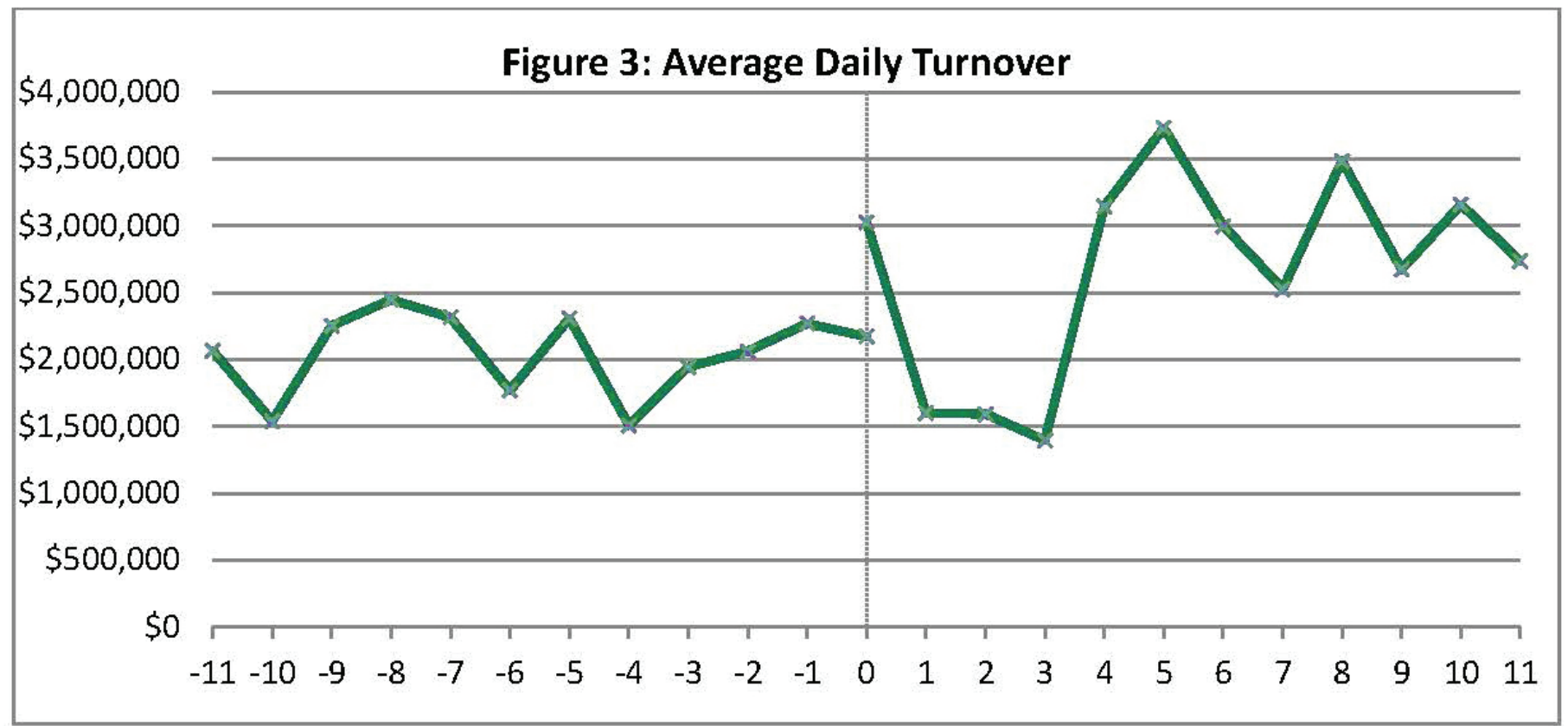

However, the matched ineligible stocks also experienced firms' turnover. Figure 4 which shows the relative average a $16 \%$ increase in turnover, and after controlling for the daily turnover of the large stocks compared to small stocks, general market improvement in turnover, the increase is highlights the improvement (deterioration) in turnover for no longer significant. This though assumes that the change larger (smaller) eligible stocks. In the pre-period large firm in turaver is uninover is under analysis, eligible small firms (less than $\$ 500$ million market This jumps to an average to more than 26 times in the capitalisation) actually experience a decline in turnover, subsequent six months. Therefore, it is the larger firms that but this decline is not evident in the ineligible matched small experience the greatest improvement in turnover.

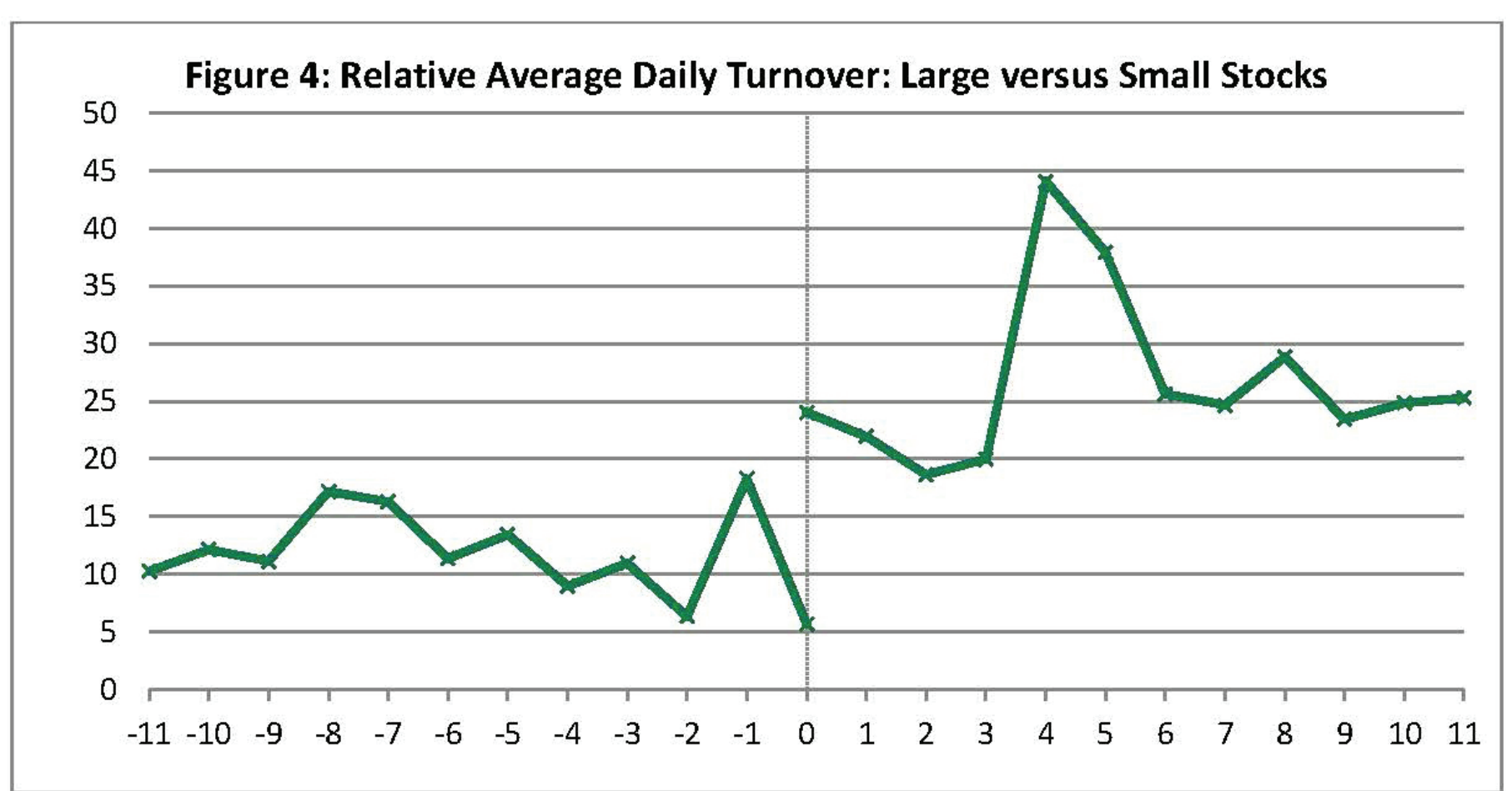

In unreported bivariate regression results ${ }^{2}$, where change confirm that smaller and less liquid stocks do not enjoy in turnover is the dependent variable and pre-period stocks the same liquidity benefits as their larger counterparts. characteristics are the independent variables, these also For example, a common illiquidity measure proposed by
Amihud (2002) is significantly negatively related to turnover. period depth enjoy significant improvements in post-period That is, stocks with lower pre-period illiquidity (i.e. are more turnover.

liquid) enjoy greater improvements in turnover in the post-period. Also, larger firms and those with greater pre-

4. Implications

This paper helps shed light on the impact of tick size in its securities markets, raising the possibility of larger size changes on firms with differing size and liquidity minimum tick size increments for some stocks. It is hoped characteristics. Relatively smaller stocks and those with that increasing tick size will increase the spread between less liquidity did not enjoy the same liquidity improvements the bid and ask quotes. Wider spreads would enhance after the minimum tick size was reduced to half-a-cent. market makers' profitability and encourage them to The economically substantial transaction cost savings increase quote size; thereby potentially improving market are predominantly captured by investors trading in larger depth and turnover. Further, the higher profits may revive stocks, and these larger stocks also enjoy significantly higher interest in funding analyst research on small stocks, which furnover comparative to small stocks. This has important maylead to incre policy decisions regarding tick size changes, and care should be taken when determining which stocks are eligible for any future tick changes.

In May 2013, the Spread Pricing Liquidity Act of 2013 (known as the Tick Size Bill) was introduced in the House by Congressman David Schweikert. The bill if passed into 列 debate surrounding tick size, particularly for smaller less average daily trading volume under 500,000 shares, the liquid stocks. While tick changes have been a one-way race ability to elect to have their stocks trade at either 5 or 10 to miniaturisation over the last two decades, the Securities cent increments. So perhaps the race for ever smaller tick Exchange Commission (SEC) is currently reviewing the tick size has been run. 


\section{References}

Ahn, H., Cao, C. Q., and Choe, H. (1996), Tick size, spread, liquidity provision on NYSE. Journal of Financial Economics and volume. Journal of Financial Intermediation 5, 2-22.

56. $125-149$

Aitken, M., and Comerton- Forde, C. (2005), Do Harris, L. E. (1994), Minimum price variation, discrete bidreductions in tick size influence liquidity? Accounting and ask spreads, and quotation sizes. The Review of Financid Finance 45, 171-184.

Amihud, Y. (2002), lliquidity and stock returns: crosssection and time-series effects. Journal of Financial Markets 5, 31-56.

Anderson, H.D. and Peng, Y. (2013). From cents to halfcents and its liquidity impact. Pacific Accounting Review Forthcoming.

Chung, K. H., Charoenwong, C., and Ding, D. K. (2004), Penny pricing and the components of spread and depth changes. Journal of Banking and Finance 28, 2981-3007.

Goldstein, M. A., and Kavajecz, K. A. (2000), Eighths, sixteenths, and market depth: changes in tick size and

\section{Appendix: Institutional Background}

The NZX announced on February 23, 2011 a pilot include 12 further stocks comprising a mixture of stocks listed programme to reduce the minimum tick size from one- on both the NZX and ASX, plus property stocks whose share cent to half-a-cent for five stocks as shown in the table price was less than $\$ 2.50$. The 12 additional stocks shown in below. Trading on the new lower tick size was effective the table below could trade at the half-cent minimum tick from the March 10, 2011. Then on October 23, 2011, the size from November 7, 2011.

NZX announced that it would extend the programme to

\begin{tabular}{ll}
\multicolumn{1}{c}{ March 10, 2011 Effective Change in Tick Size } & \multicolumn{1}{c}{ November 7, 2011 Effective Change in Tick Size } \\
\hline Auckland International Airport & Air New Zealand \\
\hline Fisher \& Paykel Appliances & AMP NZ Office \\
\hline Guinness Peat Group & Argosy Property Trust \\
\hline Kiwi Income Property Trust & CDL Investments \\
\hline Telecom & DNZ Property Fund \\
& Goodman Property Trust \\
& Infratil \\
& Kermadec Property Fund \\
& National Property Trust \\
& New Zealand Oil \& Gas \\
& Property for Industry \\
& Vital Healthcare Property Trust \\
&
\end{tabular}

Notes

This article is in part based on Anderson and Peng (2013).

2. Available from the author on request.
Corresponding Author:

Hamish Anderson, School of Economics \& Finance, Massey University

Private Bag 11222, Palmerston North New Zealand.

Email H.D.Anderson@massey.ac.nz 